\title{
Stress and fear in women living with cancer: An argumentation towards the adaptation theory
}

\author{
Ni Putu Wulan Purnama Sari \\ Department of Palliative Nursing, Faculty of Nursing, Widya Mandala Catholic University Surabaya, Indonesia
}

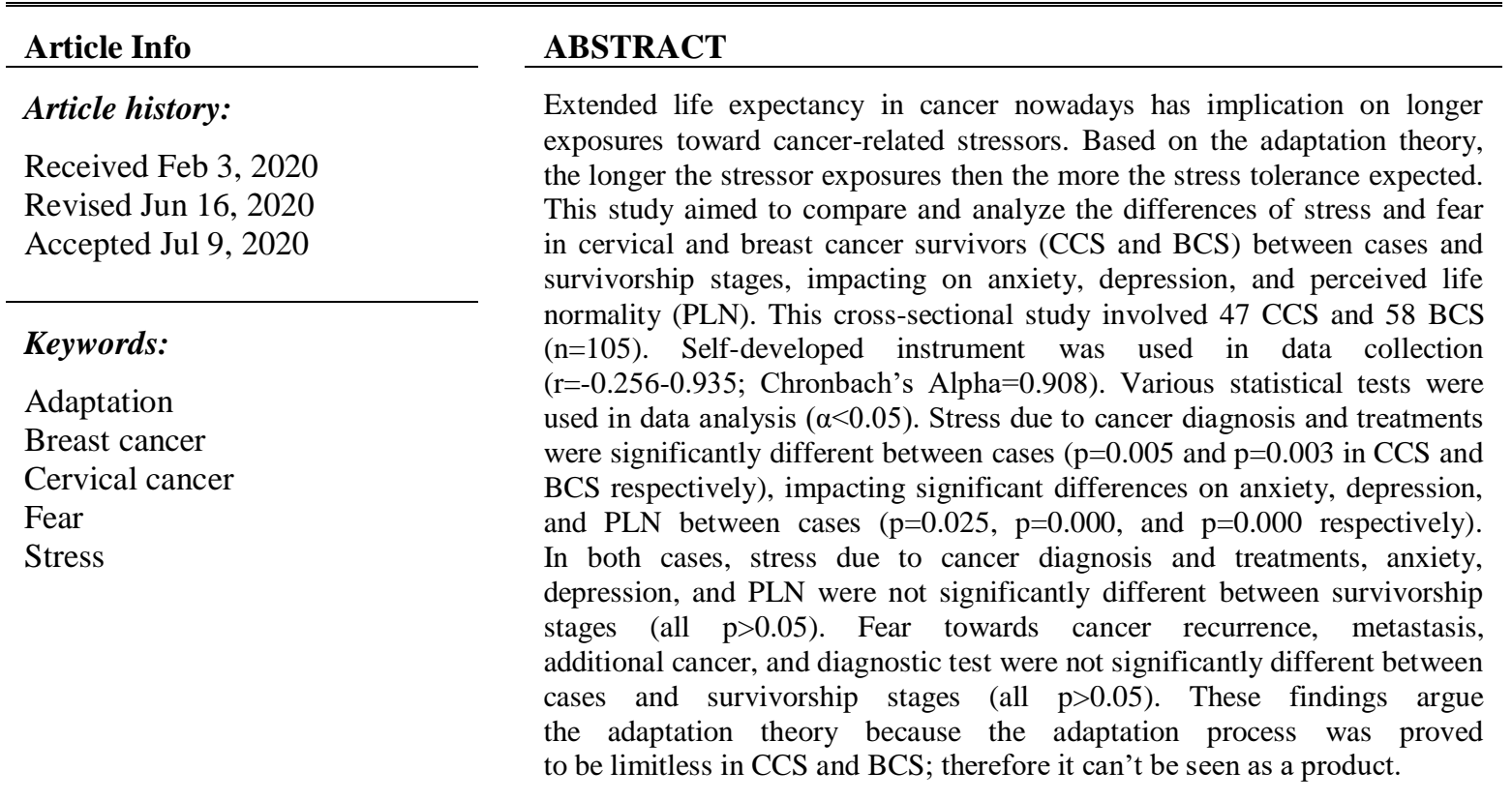

This is an open access article under the CC BY-SA license.

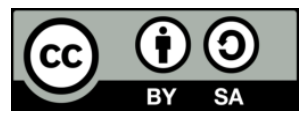

\section{Corresponding Author:}

Ni Putu Wulan Purnama Sari,

Department of Palliative Nursing,

Faculty of Nursing, Widya Mandala Catholic University Surabaya,

Jl. Raya Kalisari Selatan 1, Pakuwon City, Surabaya 60112, Indonesia.

Email: wulanpurnama@ukwms.ac.id

\section{INTRODUCTION}

Cancer involves certain genes controlling the cell regeneration process which damaged and grow abnormally [1]. Annually more than two million women globally are diagnosed with breast or cervical cancer, in which their housing, socioeconomic status, and agency dominantly determines whether she will develop one of these cancers and will ultimately survive [2]. The stage of survivorship in cancer categorizes into three, namely: acute ( $<1$ year), short term (1-5 years), and long term survivorship ( $>5$ years) [3].

Indonesia cancer prevalence was $1.4 \%$ in 2013 , in which $0.8 \%$ and $0.5 \%$ or breast and cervical cancer. The three highest prevalence provinces of cervical cancer were Riau Islands, North Maluku, and Yogyakarta (equal to 1.5\%o), while the highest prevalence province of breast cancer was Yogyakarta (equal to 2.4\%o); most women with breast and cervical cancer were found in East Java and Central Java provinces [4]. Breast cancer ranked highest for the new case and death in 2017, followed by cervical cancer in 2nd position [5] (detail explanation about Indonesia's cancer profiling in 2017 was not available online yet). 
Cervical and breast cancers have different etiology, symptoms, and complications. Cancer therapy mainly consists of surgery, chemotherapy and radiotherapy. Prior study result showed that the type of therapy between cervical and breast cancers were significantly different $(p=.000)$ [6]. Cancer diagnosis and its treatments induce stress in cancer survivors with impacts on anxiety and depression; while diagnostic test, the possibility of additional cancer, cancer recurrence and metastasis induce fear in cancer survivors impacting perceived life normality (PLN) [7]. There is a specific neurocircuitry in our brain which linking stress to fear and anxiety involving amygdale and insular cortex activation [8]. There are three parts of brain which undergo stress-induced structural remodeling and cause the changes in behavioral and physiological responses: the hippocampus, amygdala, and prefrontal cortex [9]. Stress even could limit the efficacy of behavioral therapies aimed at limiting pathological fear [10].

The expert of stress research, Hans Selye, defined stress as a nonspecific body response to any demand [11]. Every stress may leave an ineradicable scar, and individual survives from stress by being older. His stress model, the General Adaptation Syndrome (GAS), stated that there were three stages of body response towards stress: alarm, resistance, and exhaustion [12].

Adaptation and stress are two important concepts to be understood in order to understand better about individual behavior, especially for understanding the phases of illness [13]. Adaptation could be seen as a product and a process; as a product, adaptation cannot remain entirely faithful to its original form, while as a process, adaptation becomes an act of appropriating and salvaging while trying to give new meaning [14]. A well-known adaptation theory in the nursing world is the adaptation model of nursing which was developed by Sister Callista Roy in 1976. She assumed that a person is a bio-psycho-social being who is in constant interaction with a changing environment considered as an adaptive system. A person or groups who did adaptation means they use conscious awareness, self-reflection and choice to create human and environmental integration [15].

The longer people live with cancer, the more exposure towards various types of stressor they encounter physically and psychologically. The longer the exposure towards stress will be the shorter the individual lifespan [16]. In unhealthy individuals, women living with cancer for instance, the longtime exposure towards stress may worsen their health status. Correlation between psychosocial stressors and disease is influenced by the stressors (its nature, number, and persistence) and the individual's biological vulnerability (e.g. genetics, constitutional factors), psychosocial resources, and coping strategy [17]. Gender also has significant effect towards stress and its management. Women are frequently report the elevated stress level compared to men with more physical and emotional symptoms appear, but they are doing a better job than men by connecting with others better; this connection is important for making stress management strategies [18].

There is a big question about how long adaptation process happen, is there any maximum limit for that, in any context of life. The period of exposure towards stressors could determine individual stress tolerance due to adaptation process. Increase survivorship or longer life expectancy in cancer survivors have implication on longer stressor exposures by impact of prolonged psychological pain/suffering due to stress and fear, especially in long-term cancer survivors. Although stressor exposures may happen yearly in CCS and BCS, whether their stress/fear tolerances significantly improve over time along with the survivorship stages or not, it is still a big question mark. Based on the adaptation theory, it could be expected that individual stress tolerance will improve together with the progress in adaptation process. This study aimed to compare and analyze the differences of stress and fear in cervical and breast cancer survivors (CCS and BCS) between cases and stages of survivorship, with impact on anxiety, depression, and PLN. By knowing this study results, it will be beneficial for health care professionals in developing adequate multidisciplinary psychosocial intervention, and determining when is the best time to deliver it to CCS and BCS. It is important to address the psychological needs of cancer survivors to assure optimum HRQOL

\section{RESEARCH METHOD}

This cross-sectional study involved $47 \mathrm{CCS}$ and 58 BCS in the district of Rangkah, Gading, and Pacarkeling, Surabaya, Indonesia, which consisted of 27, 45, and 33 acute, short-term, and long-term survivors. In this study, more cases of breast cancer were found (more than 50\%). Since 2014 to present, breast cancer was the top leading case of female cancer in Indonesia. All study respondents expressed their agreement to participate in this study, and they had signed the consent form. Only adult, individual with confirmed cancer diagnosis, and individual on the list to be home visited regularly by palliative volunteer who were eligible to be study respondent. Those who were denied informed consent, very weak or totally bed rest, experienced extreme fatigue and losing conscious or disoriented were excluded from this study. Total sampling was applied so that sample size became 105. The head of palliative volunteer provided the patient's data, and the volunteers accompanied the researcher in doing "door to door" data collection. 
Self-developed instrument was used in data collection process. It consists of 9 items assessing stress (2 items), fear (4 items), anxiety (1 item), depression (1 item), and PLN (1 item). Psychological stress and fear in women living with cancer were assessed by the time of data collection (actual condition). Likert scale of 0 to 10 representing none to severe was used to distinguish individual response in each item: 1 (none $=0,2$ ) mild $=1-3,3$ ) moderate $=4-6$, and 4 ) severe $=7-10$; but this category was made to ease the data presentation only in result section, and not for statistical analysis purposes. After instrument testing procedure, this instrument was proved to be valid and highly reliable $(r=-0.256-0.935$; Chronbach's Alpha $=0.908)$. Data were collected since February until March, 2018. Ethical clearance was issued by Faculty of Nursing, Universitas Airlangga, Surabaya, Indonesia, with certificate number of 681-KEPK.

Descriptive statistic, independent sample $\mathrm{T}$, one way ANOVA, Mann-Whitney U, and Kruskal-Wallis $\mathrm{H}$ tests were used in data analysis $(\alpha<0.05)$. Data of fear towards diagnostic test and additional cancer, and anxiety were normally distributed $(\mathrm{p}=0.156, \mathrm{p}=0.059$, and $\mathrm{p}=0.155$ respectively), therefore parametric test was used to analyse the data (independent sample T test and one way ANOVA). In the other hand, data of stress due to cancer diagnosis and treatments, fear towards cancer recurrence and metastasis, depression, and PLN were not normally distributed (all $p<\alpha$ ), therefore nonparametric test was used to analyse the data (Mann-Whitney U and Kruskal-Wallis H tests).

\section{RESULTS AND DISCUSSION}

Most respondents were married women with lower-middle socioeconomic status, but better condition was found in the group of breast cancer. CCS was mostly older than BCS. Married CCS was mostly has no child, and more single women were found to be BCS in this study. Table 1 explains the demography characteristic of study respondents in details. The majority was long term survivors; therefore the survival rate of breast and cervical cancer is particularly long. Surgey was the top choice of therapy for BCS, while CCS was mostly underwent surgery and chemo-radiotherapy. Both cancer and its treatments were being long term stressors for most respondents. Table 2 explains the primary data of study respondents in details. Generally, cervical cancer resulted in worst stress and fear compared to breast cancer, but luckily high PLN was found most in both cases. BCS experienced less stress and fear compared to CCS, even "none" level was found in most variables. Depression and anxiety were found to be worst in CCS than BCS. The majority of both respondents agreed that among all causes, diagnostic test was the only variable which was less feared by women living with cancer. Table 3 explains the specific data of study respondents in details.

Stress due to cancer diagnosis and treatments were significantly different between cases ( $\mathrm{p}=0.005$ and $\mathrm{p}=0.003$ respectively), impacting significant differences on anxiety, depression, and PLN between cases $(\mathrm{p}=0.025, \mathrm{p}=0.000$, and $\mathrm{p}=0.000$ respectively); while fear towards cancer recurrence, metastasis, additional cancer, and diagnostic test were not significantly different between cases ( $\mathrm{p}=0.535, \mathrm{p}=0.795, \mathrm{p}=0.223$, and $\mathrm{p}=0.338$ respectively). Table 4 explains the significant differences of stress, anxiety, depression, and PLN in both groups.

Stress due to cancer diagnosis and treatments, anxiety, depression, and PLN were not significantly different between survivorship stages in both cases (CCS: $p=0.918, p=0.244, p=0.337, p=0.257$, and $\mathrm{p}=0.518$ respectively; BCS: $\mathrm{p}=0.476, \mathrm{p}=0.335, \mathrm{p}=0.519, \mathrm{p}=0.384$, and $\mathrm{p}=0.091$ respectively). Fear towards cancer recurrence, metastasis, additional cancer, and diagnostic test were also not significantly different between survivorship stages in both cases (CCS: $p=0.275, p=0.432, p=0.704$, and $p=0.144$ respectively; BCS: $\mathrm{p}=0.574, \mathrm{p}=0.645, \mathrm{p}=0.430$, and $\mathrm{p}=0.818$ respectively). All study parameters were not significantly different between survivorship stages in both cases, indicating a very slow improvement of stress/fear tolerance in the long run of survivorship period. Table 5 (A and B) explains the result of statistical analysis in details.

There are many life events inducing individual stress, one of them is physical disease, especially the chronic one [19]. Results showed that stress due to cancer diagnosis and treatments were significantly different between CCS and BCS ( $\mathrm{p}=.005$ and $\mathrm{p}=.003$ respectively), impacting significant differences on anxiety, depression, and PLN between cases ( $\mathrm{p}=.025, \mathrm{p}=.000$, and $\mathrm{p}=.000$ respectively). In the other hand, fear towards cancer recurrence, metastasis, additional cancer, and diagnostic test were not significantly different between cases (all $\mathrm{p}>\alpha$ ). These findings indicate that stress due to cancer diagnosis and treatments, anxiety, depression, and PLN are more determined by cases compared to fear towards cancer recurrence, metastasis, additional cancer, and diagnostic test which are found to be relatively similar in CCS and BCS.

Stress due to cervical cancer diagnosis $(80.85 \%$ severe stress) was found to be more severe than stress due to breast cancer diagnosis (48.28\% severe stress). Both cervical and breast cancer are chronic disease, but they could induce different stress level in women. More severe stress was found in women living with cervical cancer (CCS). This possibly happened because many CCS perceived that sexual problem could happen due to cervical cancer. A study about distress in 41 long term CCS found that $50 \%$ respondents 
reported negative impact on their life due to cervical cancer, such as significant decrements in sexual functioning; they perceived that sexual problems is the direct result of cervical cancer [20]. In cervical cancer, vaginal bleeding can occur after intercourse, pelvic pain or pain can also happen during sexual intercourse, menstruation periods sometimes last longer or are heavier than usual [21]; all of these symptoms may influence sexual functioning in CCS. The other reason is possibly because they were lack of cervical cancer-related knowledge. An exploratory study towards 16 women with cervical cancer showed that in the beginning they had low knowledge level, they experienced life crisis in term of physical disease, psychological stress, economic problems, and social isolation; it was proved that low knowledge level could result in worst cancer prevention and treatment [22].

Stress due to cervical cancer treatments $(55.32 \%$ severe stress) was found to be more severe than stress due to breast cancer treatments $(34.48 \%$ severe stress). A prior study results showed that the type of therapy between cervical and breast cancer were significantly different with $\mathrm{p}=.000$ [6]. Most CCS undertook more complex regiments, which is a combination of surgery and chemo-radiotherapy $(36.17 \%)$ if compared to most BCS who undertook surgery only (44.83\%). These findings indicate that most CCS experienced an invasive cervical cancer. More severe stress found in CCS possibly happened because regiments of cervical cancer have many side effects being a powerful stressor for women living with cervical cancer.

Table 1. Demography characteristic

\begin{tabular}{|c|c|c|c|c|c|}
\hline & \multirow{2}{*}{ Characteristic } & \multicolumn{2}{|c|}{ Cervical cancer $(n=47)$} & \multicolumn{2}{|c|}{ Breast cancer $(n=58)$} \\
\hline & & Frequency & $\%$ & Frequency & $\%$ \\
\hline \multicolumn{6}{|c|}{ 1. Age (years old) } \\
\hline & a. $<21$ & 0 & 0 & 1 & 1.72 \\
\hline & b. $21-30$ & 0 & 0 & 5 & 8.62 \\
\hline & c. $31-40$ & 5 & 10.64 & 10 & 17.24 \\
\hline & d. $41-50$ & 11 & 23.40 & 15 & 25.86 \\
\hline & e. $51-60$ & 17 & 36.17 & 15 & 25.86 \\
\hline & f. $61-70$ & 13 & 27.66 & 8 & 13.79 \\
\hline & g. $>70$ & 1 & 2.13 & 4 & 6.90 \\
\hline \multicolumn{6}{|c|}{ 2. Religion } \\
\hline & a. Catholic & 0 & 0 & 1 & 1.72 \\
\hline & b. Christian & 7 & 14.89 & 11 & 18.97 \\
\hline & c. Islam & 40 & 85.11 & 46 & 79.31 \\
\hline \multicolumn{6}{|c|}{ 3. Ethnic } \\
\hline & a. Javanese & 40 & 85.11 & 57 & 98.28 \\
\hline & b. Maduranese & 6 & 12.76 & 0 & 0 \\
\hline & c. Chinese & 1 & 2.13 & 1 & 1.72 \\
\hline \multirow[t]{6}{*}{4.} & Educational background & & & & \\
\hline & a. Primary school & 15 & 31.91 & 11 & 18.97 \\
\hline & b. Secondary school & 14 & 29.79 & 5 & 8.62 \\
\hline & c. High school & 13 & 27.66 & 26 & 44.83 \\
\hline & d. Diploma / Bachelor degree & 2 & 4.25 & 15 & 25.86 \\
\hline & e. Uneducated & 3 & 6.38 & 1 & 1.72 \\
\hline \multirow[t]{5}{*}{5.} & Marital status & & & & \\
\hline & a. Single & 3 & 6.38 & 8 & 13.79 \\
\hline & b. Married & 39 & 82.98 & 36 & 62.07 \\
\hline & c. Widow & 4 & 8.51 & 14 & 24.14 \\
\hline & d. Divorce & 1 & 2.13 & 0 & 0 \\
\hline \multirow[t]{6}{*}{6.} & Living at home with & & & & \\
\hline & a. Spouse & 39 & 82.98 & 30 & 51.72 \\
\hline & b. Children & 17 & 36.17 & 35 & 60.34 \\
\hline & c. Alone & 3 & 6.38 & 2 & 3.45 \\
\hline & d. Parents & 0 & 0 & 11 & 18.97 \\
\hline & e. Sibling & 0 & 0 & 2 & 3.45 \\
\hline \multirow[t]{7}{*}{7.} & Occupational status & & & & \\
\hline & a. Full-timer & 2 & 4.25 & 11 & 18.97 \\
\hline & b. Part-timer & 3 & 6.38 & 2 & 3.45 \\
\hline & c. Retired & 0 & 0 & 4 & 6.90 \\
\hline & d. Housewife & 40 & 85.11 & 37 & 63.79 \\
\hline & e. Seeking for a job & 0 & 0 & 1 & 1.72 \\
\hline & f. Unemployed & 2 & 4.25 & 3 & 5.17 \\
\hline \multirow[t]{5}{*}{8.} & GDP per month & & & & \\
\hline & a. Less than minimum wage & 34 & 72.34 & 34 & 58.62 \\
\hline & b. Minimum wage - IDR 5 million & 8 & 17.02 & 14 & 24.14 \\
\hline & c. More than IDR 5 million & 3 & 6.38 & 6 & 10.34 \\
\hline & d. No income & 2 & 4.25 & 3 & 5.17 \\
\hline
\end{tabular}


Table 2. Year of $1^{\text {st }}$ diagnosed with cancer, and the type of received therapy

\begin{tabular}{lcccc}
\hline \multicolumn{1}{c}{ Characteristic } & Cervical cancer $(\mathrm{n}=47)$ & \multicolumn{2}{c}{ Breast cancer $(\mathrm{n}=58)$} \\
\% & Frequency & $\%$ & Frequency & \% \\
\hline 1. Firstly diagnosed & & & & \\
a. 2018 & 0 & 0 & 4 & 6.90 \\
b. 2017 & 7 & 14.89 & 16 & 27.59 \\
c. 2016 & 12 & 25.53 & 7 & 12.07 \\
d. 2015 & 5 & 8.62 & 10 & 17.24 \\
e. 2014 & 5 & 8.62 & 3 & 5.17 \\
f. $\quad 2014$ & 18 & 38.30 & 18 & 31.03 \\
Type of therapy & & & & \\
a. Surgery & 5 & 8.62 & 26 & 44.83 \\
b. Chemotherapy & 13 & 27.66 & 8 & 13.79 \\
c. Surgery+chemotherapy & 2 & 4.25 & 11 & 18.97 \\
d. Surgery+radiotherapy & 0 & 0 & 1 & 1.72 \\
e. Chemotherapy+radiotherapy & 7 & 14.89 & 1 & 1.72 \\
f. Surgery+chemotherapy+radiotherapy & 17 & 36.17 & 5 & 8.62 \\
g. Surgery+chemotherapy+radiotherapy+analgesic & 1 & 2.13 & 0 & 0 \\
h. Surgery+chemotherapy+radiotherapy+medicine & 1 & 2.13 & 0 & 0 \\
i. Surgery+chemotherapy+oral medicine & 0 & 0 & 1 & 1.72 \\
j. Oral medicine (various types) & 0 & 0 & 4 & 6.90 \\
k. Untreated & 1 & 2.13 & 1 & 1.72 \\
\hline
\end{tabular}

Table 3. Stress, anxiety, depression, PLN, and fear in CCS and BC

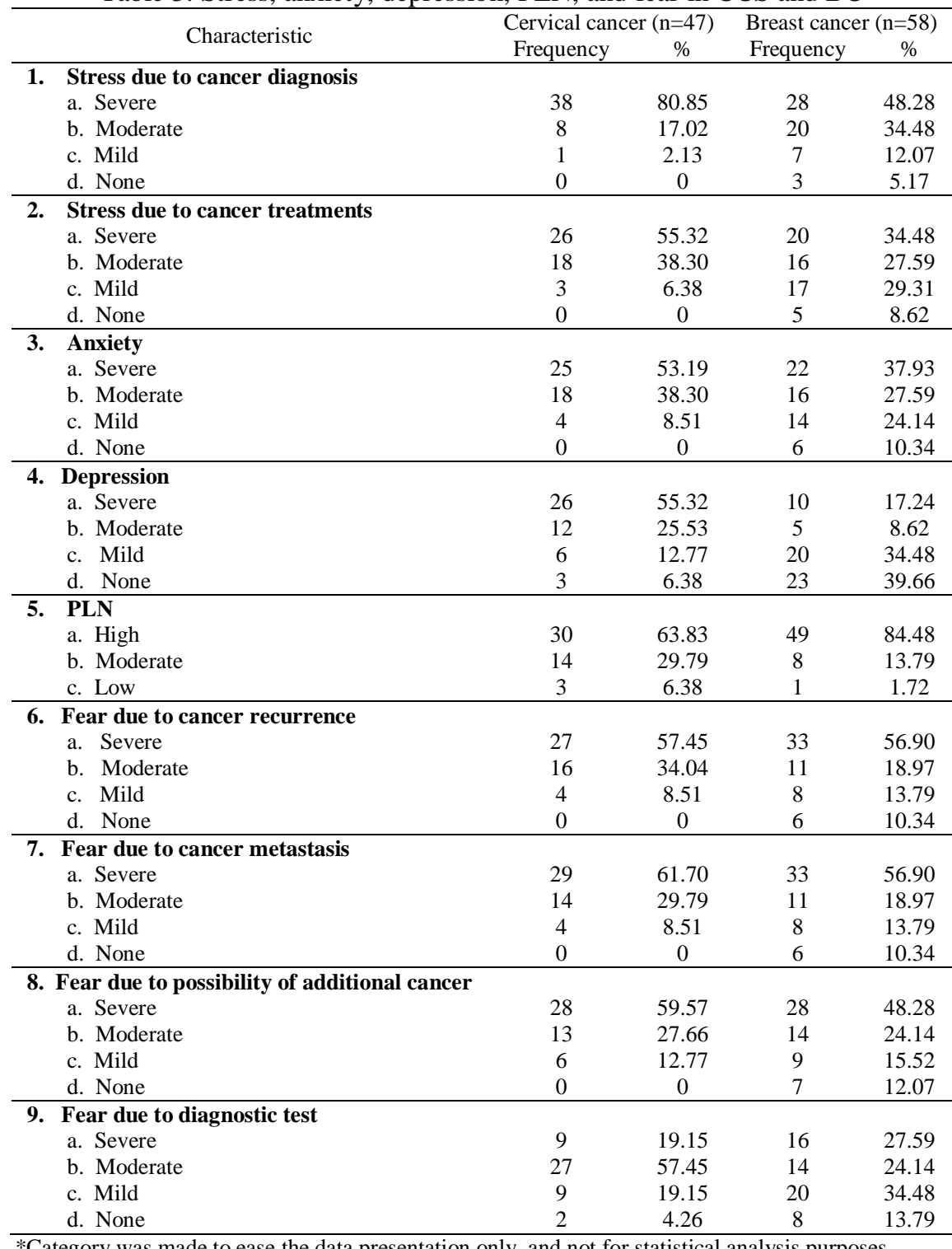

Int. J. Public Health Sci, Vol. 9, No. 3, September 2020: $272-280$ 
Table 4. Comparison of stress, anxiety, depression, PLN, and fear between cases

\begin{tabular}{|c|c|c|c|c|c|c|c|}
\hline \multirow[t]{2}{*}{ Variable } & \multicolumn{2}{|c|}{$\begin{array}{l}\text { Cervical cancer } \\
\qquad(\mathrm{n}=47)\end{array}$} & \multicolumn{2}{|c|}{$\begin{array}{l}\text { Breast cancer } \\
\quad(n=58)\end{array}$} & \multirow{2}{*}{$\begin{array}{l}\text { Mean dif. } \\
(\text { CI 95\%) }\end{array}$} & \multirow{2}{*}{$\begin{array}{c}\text { t-statistic or Z score } \\
\text { (df) }\end{array}$} & \multirow{2}{*}{$\begin{array}{c}\mathrm{p}- \\
\text { value }\end{array}$} \\
\hline & Mean & SD & Mean & SD & & & \\
\hline Stress due to cancer diagnosis & 7.45 & 1.36 & 6.09 & 2.68 & - & -2.803 & 0.005 \\
\hline Stress due to cancer treatments & 6.55 & 1.85 & 4.90 & 2.84 & - & -2.926 & 0.003 \\
\hline Anxiety & 6.51 & 1.83 & 5.31 & 3.22 & $0.15-2.25$ & 2.272 & 0.025 \\
\hline Depression & 5.74 & 2.36 & 2.64 & 3.31 & - & -4.533 & 0.000 \\
\hline PLN & 6.53 & 1.65 & 8.43 & 1.86 & - & -5.431 & 0.000 \\
\hline Fear due to cancer reccurence & 6.57 & 2.04 & 6.33 & 3.58 & - & -0.620 & 0.535 \\
\hline Fear due to cancer metastasis & 6.85 & 2.12 & 6.40 & 3.58 & - & -0.260 & 0.795 \\
\hline Fear due to possibility of additional cancer & 6.64 & 2.09 & 5.91 & 3.59 & $-0.45-1.90$ & 1.225 & 0.223 \\
\hline Fear due to diagnostic test & 4.81 & 2.07 & 4.31 & 3.02 & $-0.53-01.52$ & 0.963 & 0.338 \\
\hline
\end{tabular}

Table 5. Comparison of stress, anxiety, depression, PLN, and fear between stages of cancer survivorship in both cases

\begin{tabular}{|c|c|c|c|c|c|c|}
\hline \multicolumn{7}{|l|}{ A. Cervical cancer $(n=47)$} \\
\hline Variable & 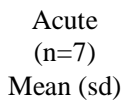 & $\begin{array}{l}\text { Short term } \\
\qquad(\mathrm{n}=23) \\
\text { Mean }(\mathrm{sd})\end{array}$ & $\begin{array}{l}\text { Long term } \\
\qquad(\mathrm{n}=17) \\
\text { Mean }(\mathrm{sd})\end{array}$ & $\begin{array}{c}\text { Mean square (CI } \\
95 \%)\end{array}$ & $\begin{array}{c}\text { F or } x^{2} \\
(d f)\end{array}$ & $\begin{array}{c}\mathrm{P}- \\
\text { value }\end{array}$ \\
\hline Stress due to cancer diagnosis & $7.43(0.79)$ & $7.56(1.41)$ & $7.29(1.53)$ & - & 0.171 & 0.918 \\
\hline Stress due to cancer treatments & $7.43(0.53)$ & $6.65(1.85)$ & $6.06(2.11)$ & - & 2.819 & 0.224 \\
\hline Anxiety & $6.57(0.98)$ & $6.87(1.79)$ & $6.00(2.09)$ & 3.711 & 1.116 & 0.337 \\
\hline Depression & $6.29(1.11)$ & $6.26(2.03)$ & $4.82(2.92)$ & - & 2.721 & 0.257 \\
\hline PLN & $7.00(1.53)$ & $6.52(1.73)$ & $6.35(1.66)$ & - & 1.316 & 0.518 \\
\hline Fear due to cancer recurrence & $6.29(1.38)$ & $6.96(2.10)$ & $6.18(2.19)$ & - & 2.584 & 0.275 \\
\hline Fear due to cancer metastasis & $7.00(1.41)$ & $7.09(2.21)$ & $6.47(2.27)$ & - & 1.680 & 0.432 \\
\hline Fear due to possibility of additional cancer & $6.57(1.40)$ & $6.83(2.25)$ & $6.41(2.18)$ & 3.258 & 0.353 & 0.704 \\
\hline Fear due to diagnostic test & $5.57(1.81)$ & $5.13(2.03)$ & $4.05(2.11)$ & 13.464 & 1.975 & 0.144 \\
\hline \multicolumn{7}{|l|}{ B. Breast Cancer $(n=58)$} \\
\hline Variable & $\begin{array}{c}\text { Acute } \\
(\mathrm{n}=20) \\
\text { Mean }(\mathrm{sd})\end{array}$ & $\begin{array}{l}\text { Short term } \\
\quad(n=22) \\
\text { Mean }(s d)\end{array}$ & $\begin{array}{l}\text { Long term } \\
\quad(\mathrm{n}=16) \\
\text { Mean (sd) }\end{array}$ & $\begin{array}{l}\text { Mean square } \\
\text { (CI 95\%) }\end{array}$ & $\begin{array}{c}\text { F or } x^{2} \\
(d f)\end{array}$ & $\begin{array}{c}\mathrm{P}- \\
\text { value }\end{array}$ \\
\hline Stress due to cancer diagnosis & $6.05(2.39)$ & $6.55(2.63)$ & $5.50(3.12)$ & - & 1.484 & 0.476 \\
\hline Stress due to cancer treatments & $4.30(2.83)$ & $5.55(3.05)$ & $4.75(2.52)$ & - & 2.185 & 0.335 \\
\hline Anxiety & $5.80(3.46)$ & $5.41(3.16)$ & $4.56(3.08)$ & 6.979 & 0.664 & 0.519 \\
\hline Depression & $3.05(3.82)$ & $3.00(3.34)$ & $1.63(2.47)$ & - & 1.916 & 0.384 \\
\hline PLN & $8.35(2.28)$ & $8.00(1.80)$ & $9.13(1.15)$ & - & 4.789 & 0.091 \\
\hline Fear due to cancer recurrence & $6.05(4.02)$ & $6.95(3.46)$ & $5.81(3.23)$ & - & 1.111 & 0.574 \\
\hline Fear due to cancer metastasis & $6.10(4.06)$ & $6.95(3.47)$ & $6.00(3.24)$ & - & 0.876 & 0.645 \\
\hline Fear due to possibility of additional cancer & $6.00(4.01)$ & $6.18(3.43)$ & $5.44(3.42)$ & 2.679 & 0.858 & 0.430 \\
\hline Fear due to diagnostic test & $4.30(3.40)$ & $4.86(3.03)$ & $3.56(2.45)$ & 7.843 & 0.202 & 0.818 \\
\hline
\end{tabular}

Cancer stage, tumor size and shape, age, overall health status, and the desire to have children in the future determine the ttreatment of cervical cancer [21]. Surgery in cervical cancer includes conization, total or radical hysterectomy, radical trachelectomy, and pelvic exenteration [21]; all of these types of surgery may influence the possibility to have children to some extends. Chemotherapy in cervical cancer uses certain chemicals aiming at killing cancer cells which are administered through intravenous injection or oral route; it may be combined with radiation, biologic drugs, or as a palliative therapy. The common side effects of chemotherapy are severe nausea and vomiting resulted in poor protein and caloric intake, even malnutrition $[23,24]$. Other than that, alopecia or hair loss usually occurs because chemotherapy attacks rapidly the dividing hair matrix cells [25]. When some chemotherapy drugs are given intravenously, they can cause the skin and veins to become discolored or darker; itching or pruritus, the dryness, flaking, or peeling caused by chemotherapy usually goes away once chemotherapy is finished [26]. Changes to fingernails and toenails are common during chemotherapy. These changes include: yellowing, brittleness and cracking, lines across the nail, partial separation of nail from the nail bed, and darkening which happen evenly across the nail if chemotherapy is given continuously [27].

Radiation in cervical cancer includes external beam radiation, internal radiation (brachytherapy), or may be used as a palliative therapy [21]. Skin problems are common in patients receiving radiotherapy. Dest (2018) stated that during radiation therapy, the skin in the treatment area may look and feel like it is sunburned. How red and irritated the skin gets depends on the dose of radiation and how sensitive your skin cells are to the radiation. Radiation therapy can cause the skin to peel, especially in skin folds such as the buttocks, under the breasts and behind the ears. It can also easily peel in areas where the skin is thin, such as on the neck. Skin in the radiation treatment area can become swollen and puffy. Radiation recall, the side effect of radiotherapy, may happen shortly or sometime after the therapy; it could be months or year

Stress and fear in women living with cancer: An argumentation towards... (Ni Putu Wulan Purnama Sari) 
after it. It is a skin reaction by symptoms of reddish, tender, peel or blister like sunburns, which may also appear when certain chemotherapy drugs, e.g. Doxorubicin, are given after radiotherapy [28].

Because of significant differences were found between CCS and BCS regarding stress due to cancer diagnosis and treatments, therefore anxiety, depression, and PLN were also found to be significantly different between cases. Psychological stress was positively correlated with depression and anxiety in cancer, in which resilience partially mediated this correlation [29]. Therefore, resilience development should be included in the prevention of depression and anxiety in cancer treatment. More severe anxiety (53.19\% severe anxiety) and more depressed women (55.32\% severe depression) were found to live with cervical cancer in this study. This possibly happened because they had less hope, optimism, and general self-efficacy. A study towards 224 cervical cancer patients showed that anxiety was higher in the period of 4-6 months after diagnosis and at stage II of the disease which may be predicted by hope and optimism; in the other hand, depression was also correlated with hope, optimism, and general self-efficacy [30].

In contrary, better PLN was found in women living with breast cancer $(84.48 \%$ high PLN) due to lower level of stress, anxiety, and depression compared to CCS; even we found the absence of stress due to cancer diagnosis $(5.17 \%)$ and its treatments $(8.62 \%)$, no anxiety $(10.34 \%)$, and no depression (39.66\%). There are many factors influencing better outcomes in BCS, such as social support, age, and education level. Families were described as a primary source of multifaceted social support in BCS [31]. Reactions towards breast cancer was varied in women with older age (over the age of 65 years old) in which those reactions impacting their experiences in seeking social support at diagnosis and during treatment [32]. In this study we found BCS received more family support from their spouse, children, and parents; compared to from spouse and children only in CCS. In the other hand, younger women were found to be BCS in this study (mostly 31-60 years old) compared to CCS (mostly 41-70 years old). Most BCS also better educated than CCS (high school to university graduated vs. primary-secondary-high school graduated). A study towards 238 cancer survivors showed that social support mainly came from the family compared to other sources, the more family support received then the higher quality of life level and the more positive affect showed; special others support was strongly negative correlated with negative affect in women living with cancer; society support was strongly positive correlated with quality of life level in younger cancer survivors [33].

Results also showed that stress due to cancer diagnosis and treatments, anxiety, depression, and PLN were not significantly different between survivorship stages both in CCS and BCS (all p $>\alpha$ ). Prior study results showed that the time of first diagnosis was significantly different between CCS and BCS $(p=.039)$, indicating significant difference also on the survivorship period between cases; time of first diagnosis was strongly correlated with the current stage of cancer $(\rho=-.409 ; p=.000)$ [6]. Although there is a tendency that survivorship period was significantly different between CCS and BCS, but their stress, anxiety, depression, and PLN were not improved along with the survivorship stages. These findings indicate a very slow improvement of stress tolerance in CCS and BCS. This possibly happened because they need more time to do the adaptation process by responding towards the cancer-related stressors, and there is no exact limit of how long the adaptation process occurs in an individual, also there is no guarantee of low long they will survive. Individual response towards stressor may be influenced by physiological function, personality, and behavior characteristic [19]. In the case of female cancer, physiological function may impair to some extends. It could be reflected by clinical manifestations occur. Prior study results showed that more severe fatigue, appetite changes, pain, sleep disturbance, constipation, nausea-vomiting, and menstrual changes were found in CCS; in which overall physical wellbeing was significantly different between CCS and BCS (p<.001) [34]. By living with cancer for the rest of their life, it was hard for the respondents to eliminate their stress, depression, and anxiety due to cancer. In the other hand, personality and behavior characteristic were not identified in this study.

Other than stress, fear also being a focus of this study. Results showed that fear towards cancer recurrence, metastasis, additional cancer, and diagnostic test were not significantly different between cases and survivorship stages in CCS and BCS (all $p>\alpha$ ). These findings indicate that for women living with cancer, whatever the type of cancer is, cancer-related fear was similar; even there is no significant improvement in the long run of cancer survivorship. An exploratory study towards 30 BCS showed that higher fear towards cancer recurrence associated with pain, suffering, and death; they described using distraction and avoidance and fewer coping skills [35]. Another exploratory study towards 27 BCS showed that $49 \%$ respondents used passive or avoidant coping styles [36]. Lazarus \& Folkman suggested there are two types of coping responses: emotion-focused and problem-focused coping [19]. It seemed that BCS who had fear especially towards cancer recurrence frequently used emotion-focused coping.

Study about fear towards cancer metastasis, additional cancer, and diagnostic test is none to be found, opening a great chance for world researchers to conduct studies in these fields. Other than fear towards cancer recurrence, metastasis, additional cancer, and diagnostic test, a meta-synthesis study towards 
78 studies from USA, UK, and Australia revealed what does people fear about cancer. Fear towards cancer may happen due to the core view of cancer as an unpredictable and indestructible enemy. Cancer may rise four types of fear: its proximity, the (lack of) strategies to keep it at a distance, the personal and social implications of succumbing, and dying from the disease [37]. More studies about fear was found in the area of breast cancer $(41 \%)$ compared to cervical cancer $(23 \%)$, also opening a great chance for world researchers to conduct studies in the area of cervical cancer.

All study parameters were not significantly different between survivorship stages in CCS and BCS, indicating very slow improvement of stress/fear tolerance in the long run of survivorship, especially in women living with female cancer. By the end of this study, the big question about how long adaptation process happen and is there any maximum limit for that, in the context of women living with cervical or breast cancer, remains unanswered. If the adaptation process is limitless, then we could not see adaptation as a product in the case of cervical and breast cancers; it will remains as a process forever.

\section{CONCLUSION}

Stress due to cancer diagnosis and treatments were significantly different between CCS and BCS, impacting significant differences on anxiety, depression, and PLN between cases. Stress due to cancer diagnosis and treatments, anxiety, depression, and PLN were not significantly different between survivorship stages both in CCS and BCS. Fear towards cancer recurrence, metastasis, additional cancer, and diagnostic test were not significantly different between cases and survivorship stages. Study findings indicate a very slow improvement in stress/fear tolerance in the long run of survivorship period. These study findings argue the existed adaptation theory because adaptation as a process was proved to be limitless in the context of women living with cancer, especially in term of psychological stress and fear, so that it will be very difficult to see adaptation as a product. Women living with cancer continuously need psychological support to reduce stress/fear response along the survivorship period. Community nurses need to collaborate with their families, psychologist, or even psychiatrist to some extent, to address these psychological needs.

\section{ACKNOWLEDGEMENTS}

This study was funded by the Center of Food and Nutritional Research, Institute of Research and Community Service, Widya Mandala Catholic University Surabaya, by Grant number: 077a/WM01.5.2/N/2018. This publication was supported by Faculty of Nursing, Widya Mandala Catholic University Surabaya.

\section{REFERENCES}

[1] M. Kaplan, “The Hispanic Outlook in Higher Education,” Paramus, vol. 18, no. 17, pp. 42-44, 2008.

[2] O. Ginsburg, et al., "The Global Burden of Women's Cancers: A Grand Challenge in Global Health," The Lancet Series: Health, Equity, and Women's Cancers, vol. 2, no. 389(10071), pp. 847-860, 2017.

[3] R. A. Campo, et al., "Weathering The Seasons of Cancer Survivorship: Mind-Body Therapy Use and Reported Reasons and Outcomes by Stages of Cancer Survivorship," Supportive Care in Cancer Survivorship, vol. 24, no. 9 , pp. 3783-3791, 2016.

[4] Ministry of Health, Republic of Indonesia, "National Cancer Situation in 2013 (in Bahasa Indonesia), 2015. Retrieved from: http://www.depkes.go.id/resources/download/pusdatin/infodatin/infodatin-kanker.pdf

[5] M. M. Demment, et al., "Developing The Evidence Base to Inform Best Practice: A Scoping Study of Breast and Cervical Cancer Reviews in Low-And Middle-Income Countries," PLoS ONE, vol. 10, no. 9, pp. e0134618, 2015.

[6] N. P. W. P. Sari, "Women Living with Breast and Cervical Cancer in The Community: The Face of Surabaya Nowadays," Indonesian Journal of Cancer, vol. 12, no. 4, pp. 116-122, 2018.

[7] B. R. Ferrel BR, K. Hassey-Dow, M. Grant, "Measurement of The Quality of Life in Cancer Survivors," Quality of Life Research, vol. 4, pp. 523-531, 1995.

[8] L. M. Shin, I. Liberzon, "The Neurocircuitry of Fear, Stress, and Anxiety Disorders," Neuropsychopharmacology Reviews, vol. 35, pp. 169-191, 2010.

[9] B. S. McEwen, "Physiology and Neurobiology of Stress and Adaptation: Central Role of The Brain," Physiological Reviews, vol. 87, no. 3, pp. 873-904, 2007.

[10] S. Maren, A. Holmes, "Stress and Fear Extinction," Neuropsychopharmacology, vol. 41, no. 1, pp. 1-22, 2015.

[11] S. Y. Tan, A. Yip, "Hans Selye (1907-1982): Founder of The Stress Theory," Singapore Med J., vol. 59, no. 4, pp. 170-171, 2018.

[12] H. Lucille, "General Adaptation Syndrome (GAS) Stages," 2016. Retrieved from: https://www.integrativepro.com/resources/integrative-blog/2016/general-adaptation-syndrome-stages

[13] R. J. Ursano, "Stress and Adaptation: The Interaction of The Pilot Personality and Disease," Aviat Space Environ Med., vol. 51, no. 11, pp. 1245-1249, 1980. 
[14] M. E. Kinney, "Linda Hutcheon's A Theory of Adaptation,” by Linda Hutcheon, New York: Routledge, 2006. [vi, 273, 0415967953, \$42.95.] Preface, references, index. Critical Voices: The University of Guelph Book Review Project, 2013. Retrieved from: https://journal.lib.uoguelph.ca/index.php/sofammj/article/view/2655/3015

[15] Nursalam, "Research Methodology in Nursing Science: Practical Approach (in Bahasa Indonesia), $3^{\text {rd }}$ Ed.," Jakarta: Salemba Medika, 2013.

[16] E. S. Epel, G. J. Lithgow, "Stress Biology and Aging Mechanisms: Toward Understanding the Deep Connection between Adaptation to Stress and Longevity," J Gerontol A Biol Sci Med Sci., vol. 69, no. 1, pp. S10-S16, 2014.

[17] N. Schneiderman, G. Ironson, S. D. Siegel, "Stress and Health: Psychological, Behavioral, and Biological Determinants," Annu Rev Clin Psychol., vol. 1, pp. 607-628, 2005.

[18] American Psychological Association, "Gender and Stress," 2010. Retrieved from: https://www.apa.org/news/press/releases/stress/2010/gender-stress.aspx

[19] I. W. Candra, I. A. Harini, I. N. Sumirta, "Psychology: The Scientific Foundation of Mental Health Nursing Practice (in Bahasa Indonesia), $1^{\text {st }}$ Ed.," Yogyakarta: ANDI, 2017.

[20] C. C. Gotay, et al., "Adaptation and Quality of Life among Long-Term Cervical Cancer Survivors in The Military Health Care System," Military Medicine, vol. 173, no. 10, pp. 1035-1041, 2008.

[21] American Cancer Society (ACS), "Cervical Cancer," Smart Engage: In Depth Report, USA: Johns Creek, 2017.

[22] C. Binka, D. T. Doku, K. Awusabo-Asare, "Experiences of Cervical Cancer Patients in Rural Ghana: An Exploratory Study," PLoS ONE, vol. 12, no. 10, pp. e0185829, 2017.

[23] N. Sutandyo, "Nutrition in Cancer Patients Who Receive Chemotherapy (in Bahasa Indonesia)," Indonesian Journal of Cancer, vol. 4, pp. 144-148, 2007.

[24] S. K. Lara, U. E. Morales, M. D. Kuba, D. Green, "Gastrointestinal Symptoms and Weight Loss in Cancer Patients Receiving Chemotherapy,” Br J Nutr., DOI: 10.1017/S000711451200203, 2012.

[25] R. Paus, I. S. Haslam, A. A. Sharov, V. A. Botchkarev, "Pathobiology of Chemotherapy-induced Hair Loss," Lancet Oncol., vol. 14, pp.e50, 2013.

[26] D. Camp-Sorrell, "Chemotherapy Toxicities and Management," Yarbro CH, Wujcki D, Holmes GB, (eds.)., Cancer Nursing: Principles and Practice, $8^{\text {th }}$ Edition, Burlington, MA: Jones and Bartlett Learning, vol. 16, pp. 497-554, 2018.

[27] L. Morse, "Skin and Nail Bed Changes," Yarbro, CH., Wujcik, D., Holmes, GB., (eds.), Cancer Symptom Management, $4^{\text {th }}$ Edition, Burlington, MA: Jones \& Bartlett Learning, vol. 28, pp. 587-616, 2014.

[28] V. M. Dest, "Radiation Therapy: Toxicities and Management," Yarbro, CH., Wujcki, D., Holmes, GB., (eds.). Cancer Nursing: Principles and Practice, $8^{\text {th }}$ Edition, Burlington, MA: Jones and Bartlett Learning, vol. 13, pp. 333-374, 2018.

[29] M. Li, L. Wang, "The Associations of Psychological Stress with Depressive and Anxiety Symptoms among Chinese Bladder and Renal Cancer Patients: The Mediating Role of Resilience," PLoS ONE, vol.11, no.4, pp. e0154729, 2016.

[30] Y-L. Yang, et al., "Prevalence and Associated Positive Psychological Variables of Depression and Anxiety among Chinese Cervical Cancer Patients: A Cross-Sectional Study," PLOS ONE, vol. 9, no. 4, pp. e94804, 2014.

[31] C. Kwok, K. White, "Perceived Information Needs and Social Support of Chinese-Australian Breast Cancer Survivors," Support Care Cancer, vol. 22, no. 10, pp. 2651-2659, 2014.

[32] G. J. Yoo, et al., "Older Women, Breast Cancer, and Social Support," Support Care Cancer, vol. 18, no. 12, pp. 1521-1530, 2010.

[33] J. You, Q. Lu, "Sources of Social Support and Adjustment among Chinese Cancer Survivors: Gender and Age Differences," Support Care Cancer, vol. 22, no. 3, pp. 697-704, 2014.

[34] N. P. W. P. Sari, "Physical Wellbeing in Cervical and Breast Cancer Survivors: A Cross-Sectional Study in Surabaya, Indonesia," Indonesian Journal of Cancer, vol. 12, no. 3, pp. 80-87, 2018.

[35] B. Thewes, et al., "A Qualitative Exploration of Fear of Cancer Recurrence (FCR) amongst Australian and Canadian Breast Cancer Survivors," Support Care Cancer, vol. 24, pp. 2269-2276, 2016.

[36] J. De Vries, et al., "How Breast Cancer Survivors Cope with Fear of Recurrence: A Focus Group Study," Support Care Cancer, vol. 22, no.3, pp. 705-712, 2014.

[37] C. Vrinten, et al., "What Do People Fear About Cancer? A Systematic Review and Meta-Synthesis of Cancer Fears in The General Population," Psycho-Oncology, vol.26, no.8, pp. 1070-1079, 2017. 